\section{Citologia de impressão conjuntival em crianças desnutridas graves hospitalizadas}

\section{Conjunctival impression cytology in children hospitalized with severe malnutrition}

Larissa Albuquerque Paiva 1

Ana Rodrigues Falbo 2

Maria de Fátima Costa Caminha 3

Margarida Maria de Freitas Lola 4

Ilma Kruze Grande de Arruda 5

Malaquias Batista Filho 6

1-3,6 Instituto de Medicina Integral Prof. Fernando Figueira. Rua dos Coelhos, 300. Boa Vista. Recife, PE, Brasil. CEP: 50.070-550. E-mail: fatima_caminha@hotmail.com

4 Centro de Investigação em Micronutrientes. Universidade Federal da Paraíba. João Pessoa, PB, Brasil.

5 Departamento de Nutrição. Universidade Federal de Pernambuco. Recife, PE, Brasil.

\section{Resumo}

Objetivo: avaliar os achados da citologia de impressão conjuntival (CIC) em crianças com desnutrição energético protéica (DEP) grave, hospitalizadas no Instituto de Medicina Integral Prof. Fernando Figueira (IMIP).

Métodos: estudo descritivo, tipo série de casos, realizado no período de agosto de 2005 a maio de 2006, envolvendo 41 crianças de um a 60 meses, com desnutrição grave (pesolaltura $<-3 D P$ elou edema padrão NCHS). A técnica para a realização da CIC seguiu normas padronizadas segundo estudo de validação. A leitura das lâminas foi realizada por dois observadores independentes.

Resultados: a idade dos casos variou de um a 47 meses, com a mediana de nove meses. Observou-se padrão de anormalidade da CIC em 46,3\% das crianças. Entre os casos com CIC anormal (marginal (-) e deficiente), 40\% apresentaram edema.

Conclusões: a prevalência elevada de resultados anormais de CIC, resumindo as classificações marginal (-) e padrão deficiente, justifica, na experiência aqui relatada, o cuidado normativo de se utilizar doses elevadas de vitamina A no tratamento hospitalar de desnutridos graves.

Palavras-chave Transtornos da nutrição infantil, Deficiência de vitamina A, Conjuntiva, Citologia, Xeroftalmia 


\section{Introdução}

A deficiência de vitamina A (DVA) constitui ainda um grave problema de saúde pública no mundo, sendo a principal causa de cegueira prevenível em crianças de países em desenvolvimento, especialmente na África e no sudeste da Ásia. ${ }^{1}$ Estima-se que 127 milhões de crianças em idade pré-escolar acham-se expostas aos riscos de DVA no mundo, com 4,4 milhões de casos de xeroftalmia. Deste total de 127 milhões, cerca de 6,5\% vivem nas Américas, incluindo o Brasil.2,3 Estima-se que, mundialmente, cerca de um milhão de óbitos infantis anuais estejam associados à carência de vitamina A..$^{3,4}$ Segundo a World Health Organization (WHO), o Brasil se classifica como área de ocorrência de hipovitaminose $\mathrm{A}$ subclínica grave, ${ }^{4}$ mas essa categorização tem sido fundamentada em dados pontuais que podem não traduzir a realidade do país, 5 e em poucos estudos de base populacional.6,7

A vitamina A exerce funções importantes em vários sistemas e processos do organismo, de modo que um estado de carência pode causar alterações visuais, na diferenciação celular (substituição de células produtoras de muco por células produtoras de queratina), na embriogênese (malformações congênitas), na resposta imune (integridade do sistema epitelial), no crescimento músculoesquelético, na hematopoiese (anemia) e na reprodução, entre outras. 8

No que concerne à avaliação do problema, a dosagem sérica de retinol é o parâmetro mais largamente utilizado na mensuração do estado orgânico da vitamina A. Todavia, esse método, além das dificuldades de aplicação correta, nem sempre reflete a verdadeira situação dos níveis desse micronutriente no organismo, pelo fato de somente diminuir quando os estoques orgânicos se acham bastante reduzidos. Ademais, os níveis séricos de retinol podem sofrer influência de outros fatores, como a síntese protéica inadequada na desnutrição energético-protéica (DEP) e a resposta a infecções ou doenças inflamatórias, os quais levam à redução dos níveis de retinol circulantes, mesmo na presença de estoques adequados de vitamina A. 8,9

Em artigo de revisão, Calonge et al. ${ }^{10}$ descrevem que a citologia de impressão conjuntival (CIC) representa a técnica de escolha para amostras da superfície epitelial ocular, por ser um procedimento minimamente invasivo e utilizar células epiteliais bem preservadas da superfície ocular. Com o emprego dessa técnica, em crianças iranianas, Rostami et al. 1 encontraram uma especificidade de $94 \%$ e uma sensibilidade de $93 \%$ no diagnóstico da
DVA. A classificação de seus resultados se baseia na presença, forma e quantificação das células epiteliais caliciformes, assim como o depósito de mucina na conjuntiva examinada. ${ }^{11-13}$

Considerando que a DVA é um co-fator muito importante na ocorrência de formas graves de desnutrição e no seu desenlace, a WHO, em protocolo normativo do tratamento hospitalar destes casos, inclui a administração de vitamina $\mathrm{A}$, sob a forma de fármacos, como uma das medidas de rotina a serem observadas. Uma vez que o Instituto de Medicina Integral Prof. Fernando Figueira (IMIP) mantém uma enfermaria especial para o tratamento hospitalar de crianças portadoras de formas graves de desnutrição, incluindo, em caráter avaliativo, o protocolo proposto pela $\mathrm{WHO}$, considerou-se oportuno e pertinente avaliar a situação da DVA mediante a citologia de impressão conjuntival. É este, portanto, o objetivo básico do presente estudo.

\section{Métodos}

Foi realizado um estudo do tipo série de casos, no período de agosto de 2005 a maio de 2006, envolvendo 41 crianças de um a 60 meses de idade, hospitalizadas no IMIP em Recife, Pernambuco. Foram admitidos como critérios de inclusão as formas graves de desnutrição protéico-calórica (índice peso/altura menor que -3 escores-z, tendo como referência o padrão do National Center for Health Statistics (NCHS), 14 recomendado pela WHO e/ou presença de edema simétrico envolvendo no mínimo os pés), assim como a permissão de participação da criança no estudo pelo responsável legal. Inicialmente foram selecionadas 48 crianças, sendo sete excluídas em decorrência da não realização do exame: quatro pela não sedação com o hidrato de cloral (duas pela gravidade do quadro clínico e duas pela falta de resposta à droga), uma pela evolução para óbito antes da realização do exame, uma por apresentar conjuntivite e uma por evasão do serviço.

Para coleta dos dados foi utilizado um formulário reunindo variáveis sociodemográficas (local de residência, água encanada, fossa séptica, recolhimento de lixo, renda familiar per capita e escolaridade materna), biológicas e clínicas referentes às crianças (sexo, prematuridade, peso ao nascer, administração prévia de vitamina $\mathrm{A}$, internamento por pneumonia, diarréia, presença de edema e doença de base, definida como a condição clínica de maior relevância patológica, provadamente com implicação no próprio desenvolvimento da desnutrição grave). A aplicação do formulário para os pais e/ou responsáveis pelas crianças foi efetuada após o 
consentimento livre e esclarecido.

$\mathrm{O}$ peso das crianças menores de dois anos foi aferido em balança marca Filizola, modelo BP baby 6767-00 (Indústrias FILIZOLA S/A, São Paulo, Brasil), com capacidade máxima de $15 \mathrm{~kg}$ e precisão de $5 \mathrm{~g}$; o comprimento, mediante o uso de um antropômetro horizontal (Misura Per Sarti, C\&C, São Paulo, Brasil) com $130 \mathrm{~cm}$ de extensão e precisão de $0,1 \mathrm{~cm}$. Nas crianças com dois anos e mais, utilizou-se balança de plataforma eletrônica, marca Toledo, modelo 6063866 (Toledo do Brasil Indústria de Balanças Ltda, São Paulo, Brasil), carga máxima $150 \mathrm{~kg}$ e mínima de $0,125 \mathrm{~kg}$ e precisão de $0,05 \mathrm{~kg}$; a estatura foi aferida mediante o uso de antropômetro acoplado à própria balança, com 2,01 $\mathrm{m}$ de extensão e precisão de $0,1 \mathrm{~cm}$.

As crianças do estudo foram submetidas a exame sob sedação (hidrato de cloral 5\%: $50 \mathrm{mg} / \mathrm{kg} / \mathrm{dose}$ por via oral) na enfermaria do IMIP. Foi utilizado papel de acetato de celulose (HAWP 304F0, Millipore), previamente cortado (3 x $25 \mathrm{~mm}$ ), acondicionado em recipiente hermeticamente fechado, protegido do calor e umidade.

O papel filtro foi aplicado e aderido durante três a cinco segundos na região temporal da conjuntiva ocular bulbar. Após sua retirada rápida e suavemente, fez-se imediatamente a transferência das amostras de camadas de células epiteliais para uma lâmina imprint, previamente identificada (nome do paciente, data, olho examinado e área coletada). Tentou-se realizar o procedimento para os dois olhos.

Completada a coleta, a lâmina foi imersa durante, no mínimo, 15 minutos em uma solução para fixação e coloração composta de oito volumes de fucsina fenicada (solução de Ziehl-Nielsen), 16 volumes de azul de Alcian a $0,2 \%$ em ácido acético a $5 \%$ e um volume de álcool etílico a $95 \%$ para fixação. Retirou-se, então, o excesso de corante em água corrente, sendo as lâminas expostas para secagem natural. Após esta operação, as lâminas foram acondicionadas em estojos apropriados.

Para análise histológica do material coletado foram utilizados microscópio óptico, procedendo-se a classificação diagnóstica segundo os critérios descritos a seguir:

Classificação diagnóstica da CIC:11

Padrão normal:

Células epiteliais $=$ pequenas agregadas. Relação núcleo/citoplasma grande.

Células caliciformes $=$ presentes em grande quantidade.

Depósito de mucina $=$ Presentes em grande quantidade.
Padrão marginal (+):

Células epiteliais $=$ pequenas agregadas, formando ilhas. Relação núcleo/citoplasma tende a diminuir.

Células caliciformes $=$ raras

Depósito de mucina $=$ raro.

Padrão marginal (-):

Células epiteliais $=$ alargadas, algo dispersas e desagregadas. Relação núcleo/citoplasma tende a diminuir.

Células caliciformes $=$ ausentes .

Depósito de mucina $=$ ausente.

Padrão deficiente:

Células epiteliais $=$ grandes, isoladas e dispersas . Núcleo picnótico.

Células caliciformes $=$ ausentes.

Depósito de mucina $=$ ausente.

Para analisar dicotomicamente os resultados considerou-se como normal o agrupamento dos padrões normal e marginal positivo e, como anormal, a reunião das outras duas classificações.

A avaliação do padrão histológico das lâminas foi feita por dois observadores, sendo um deles uma bioquímica especialista na aplicação desse método. A concordância interobservador foi analisada calculando-se o coeficiente de Kapa, que resultou no valor de 0,80 , indicando, portanto, uma boa concordância.

Os dados foram analisados utilizando o software EPI-INFO versão 6.0. Para análise do estado nutricional, foi utilizado o EPINUT, módulo do EPIINFO, com o padrão do NCHS.14 As variáveis categóricas foram sumarizadas utilizando a distribuição de frequências simples e absolutas.

O projeto desta pesquisa foi aprovado pelo Comitê de Ética em Pesquisa do IMIP em reunião realizada em abril de 2004.

\section{Resultados}

Em relação à citologia de impressão conjuntival foi observado que $46,3 \%$ das crianças apresentaram achados compatíveis com um padrão anormal, somando-se as classificações marginal (-) e deficiente.

Quanto à condição socioeconômica, 60,9\% das crianças residiam no interior do Estado, em casas com água encanada $(61,0 \%)$, fossa séptica $(68,3 \%)$ e recolhimento de lixo $(61,0 \%)$. Em relação à renda familiar per capita, 97,5\% das famílias viviam com menos de um salário mínimo. No que concerne à escolaridade, $17,5 \%$ das mães eram analfabetas e $65,0 \%$ tinham quatro ou menos anos de escolaridade com aprovação (Tabela 1).

A idade das crianças variou de um a 47 meses, 
Distribuição de frequência das crianças com desnutrição grave hospitalizadas no Instituto de Medicina Integral Prof. Fernando Figueira, segundo variáveis das condições socioeconômicas e ambientais. Recife, 2005 a 2006.

\begin{tabular}{|c|c|c|}
\hline Variáveis & $\mathbf{N}$ & $\%$ \\
\hline \multicolumn{3}{|l|}{ Local da residência } \\
\hline Região metropolitana do Recife & 14 & 34,1 \\
\hline Interior do Estado & 25 & 60,9 \\
\hline Outro Estado & 02 & 4,8 \\
\hline \multicolumn{3}{|l|}{ Água encanada } \\
\hline Sim & 25 & 61,0 \\
\hline Não & 16 & 39,0 \\
\hline \multicolumn{3}{|l|}{ Fossa séptica } \\
\hline $\operatorname{sim}$ & 28 & 68,3 \\
\hline Não & 13 & 31,7 \\
\hline \multicolumn{3}{|l|}{ Recolhimento de lixo } \\
\hline Sim & 25 & 61,0 \\
\hline Não & 16 & 39,0 \\
\hline \multicolumn{3}{|l|}{ Renda familiar per capita $(\mathrm{SM})^{\star *}$} \\
\hline$<0,25$ & 34 & 82,9 \\
\hline $0,25-0,49$ & 5 & 12,2 \\
\hline $0,5-0,99$ & 1 & 2,4 \\
\hline$\geq 1$ & 1 & 2,4 \\
\hline \multicolumn{3}{|l|}{ Escolaridade materna* } \\
\hline Nenhuma & 7 & 17,5 \\
\hline 1 a 4 anos & 19 & 47,5 \\
\hline 5 a 8 anos & 13 & 32,5 \\
\hline 9 anos ou mais & 1 & 2,5 \\
\hline
\end{tabular}

* A não correspondência com o número total da amostra deve-se a ausência de informação para a variável estudada; ** $\mathrm{SM}=$ salário mínimo $=\mathrm{R} \$ 300,00$

com a mediana de nove meses $\left(1^{\circ}\right.$ quartil $=4$ meses, $3^{\circ}$ quartil $=17$ meses $)$.

No conjunto das observações, houve um pequeno predomínio do sexo masculino $(58,5 \%)$. Antecedentes de prematuridade foram constatados em $27,5 \%$ dos casos. Das crianças com DEP grave, $65,8 \%$ nasceram com menos de 3000 gramas, sendo $39,4 \%$ classificados em categorias de muito baixo peso $(<1500 \mathrm{~kg}$ ) e baixo peso (entre $1500 \mathrm{~kg}$ e 2449 $\mathrm{kg}$ ). Vinte por cento dessas crianças nunca foram amamentadas. Administração prévia de vitamina A foi constatada em 35,9\% dos casos (Tabela 2).

Os principais motivos da hospitalização foram a diarréia $(46,3 \%)$ e a pneumonia $(31,7 \%)$. A presença de edema ou doença crônica associada foi observada em pouco mais de $40,0 \%$ das crianças. Duas crianças (4,9\%) evoluíram para o óbito (Tabela 2).

Em relação às 19 crianças com CIC anormal, nove apresentavam edema $(47,4 \%)$, oito uma doença de base associada (42,1\%). Em aproximadamente um terço o motivo da admissão foi diarréia ou pneumonia (36,8\%), registrando-se antecedentes de prematuridade e peso insuficiente ao nascer em, respectivamente, $16,6 \%$ e $52,9 \%$ dos casos. Seis crianças receberam vitamina $\mathrm{A}(35,2 \%)$ em período que variou de dois a 11 meses prévios ao internamento (Tabela 3). 
Distribuição de frequência das crianças com desnutrição grave hospitalizadas no Instituto de Medicina Integral Prof. Fernando Figueira, segundo variáveis biológicas e clínicas. Recife, 2005 a 2006.

\begin{tabular}{|c|c|c|}
\hline Variáveis & $\mathbf{N}$ & $\%$ \\
\hline \multicolumn{3}{|l|}{ Sexo } \\
\hline Masculino & 24 & 58,5 \\
\hline Feminino & 17 & 41,5 \\
\hline \multicolumn{3}{|l|}{ Prematuridade* } \\
\hline Sim & 11 & 27,5 \\
\hline Não & 29 & 72,5 \\
\hline \multicolumn{3}{|l|}{ Peso ao nascer $(\mathrm{Kg})$} \\
\hline$<1500$ & 4 & 10,5 \\
\hline $1500-2499$ & 11 & 28,9 \\
\hline $2500-2999$ & 10 & 26,3 \\
\hline$\geq 3000$ & 13 & 34,2 \\
\hline \multicolumn{3}{|c|}{ Administração prévia de vitamina $\mathrm{A}$} \\
\hline Sim & 14 & 35,9 \\
\hline Não & 25 & 64,1 \\
\hline \multicolumn{3}{|c|}{ Internamento por pneumonia } \\
\hline Sim & 13 & 31,7 \\
\hline Não & 28 & 68,3 \\
\hline \multicolumn{3}{|c|}{ Internamento por diarréia } \\
\hline Sim & 19 & 46,3 \\
\hline Não & 22 & 53,7 \\
\hline \multicolumn{3}{|c|}{ Presença de edema } \\
\hline Sim & 18 & 43,9 \\
\hline Não & 23 & 56,1 \\
\hline \multicolumn{3}{|l|}{ Doença de base } \\
\hline Sim & 18 & 43,9 \\
\hline Não & 23 & 56,1 \\
\hline \multicolumn{3}{|l|}{ Evolução } \\
\hline Óbitos & 2 & 4,9 \\
\hline Alta hospitalar & 39 & 94,1 \\
\hline
\end{tabular}

* A não correspondência com o número total da amostra deve-se a ausência de informação para a variável estudada. 
Tabela 3

Distribuição de frequência das crianças com desnutrição grave e citologia de impressão conjuntival anormal hospitalizadas no Instituto de Medicina Integral Prof. Fernando Figueira, segundo algumas características da sua condição clínica. Recife, 2005 a 2006.

\begin{tabular}{|c|c|c|}
\hline Variáveis & $\mathbf{N}$ & $\%$ \\
\hline \multicolumn{3}{|l|}{ Edema } \\
\hline Sim & 9 & 47,4 \\
\hline Não & 10 & 52,6 \\
\hline \multicolumn{3}{|l|}{ Doença de base } \\
\hline Sim & 8 & 42,1 \\
\hline Não & 11 & 57,9 \\
\hline \multicolumn{3}{|l|}{ Diarréia } \\
\hline Sim & 7 & 36,8 \\
\hline Não & 12 & 63,2 \\
\hline \multicolumn{3}{|l|}{ Pneumonia } \\
\hline Sim & 7 & 36,8 \\
\hline Não & 12 & 63,2 \\
\hline \multicolumn{3}{|l|}{ Prematuridade } \\
\hline Sim & 3 & 16,6 \\
\hline Não & 16 & 83,4 \\
\hline \multicolumn{3}{|c|}{ Peso ao nascer $(\mathrm{Kg})^{*}$} \\
\hline$<1500$ & 1 & 5,9 \\
\hline $1500-2499$ & 4 & 23,5 \\
\hline $2500-2999$ & 5 & 29,4 \\
\hline$\geq 3000$ & 7 & 41,2 \\
\hline \multicolumn{3}{|c|}{ Aleitamento materno* } \\
\hline Nunca mamou & 8 & 20,0 \\
\hline$\leq 1$ mês & 7 & 17,5 \\
\hline$>1$ a 3 meses & 12 & 30,0 \\
\hline$>3$ a 6 meses & 7 & 17,5 \\
\hline$>6$ meses & 6 & 15,0 \\
\hline \multicolumn{3}{|l|}{ Vitamina A prévia } \\
\hline Sim & 6 & 35,2 \\
\hline Não & 13 & 64,8 \\
\hline
\end{tabular}

* A não correspondência com o número total da amostra deve-se a ausência de informação para a variável estudada. 


\section{Discussão}

$\mathrm{Na}$ caracterização socioeconômica e ambiental dos casos estudados uma observação preliminar de grande relevância se impõe: a precariedade das condições de vida das famílias dos desnutridos graves, de tal modo que, com exceção de apenas um caso $(2,4 \%)$, todas as crianças pertenciam a famílias com renda per capita abaixo de um salário mínimo. A baixa escolaridade materna e as condições desfavoráveis do saneamento foram bem mais desfavoráveis que os resultados de estudos de base populacional efetuados no Estado de Pernambuco ${ }^{15}$ ou no Nordeste Brasileiro, 16 tornando-se bem demonstrativos do quadro de penúria das famílias dos desnutridos graves, denotando, portanto, uma situação muito peculiar de elevada vulnerabilidade social que particulariza o risco familiar das formas avançadas de desnutrição.

Como parte do mesmo contexto e, ao mesmo tempo, como consequência imediata ou indireta da ocorrência da desnutrição grave da série de casos, a concomitância de $27,5 \%$ de prematuridade e de $39,4 \%$ de baixo peso ao nascer representam achados também excepcionalmente elevados, em comparação com o que acontece em Pernambuco 17 ou no Brasil.18 De fato, estes valores acham-se quatro a cinco vezes mais elevados que as frequências esperadas como previsão epidemiológica.

Por si, a associação entre a pobreza extrema e as adversidades biológicas da prematuridade e do baixo peso ao nascer, em grande parte atribuídos à própria desnutrição materna no curso da gravidez, 19 estabelecem vulnerabilidades fundamentais para compreender a condição de desnutrição grave e, por extensão, do risco de DVA encontrado pela prova da CIC. Na realidade, os dois problemas (desnutrição grave e DVA, na forma clínica ou subclínica), se tornam eventos raros em estudos de base populacional, de tal forma que sua ocorrência praticamente se restringe aos serviços hospitalares, ${ }^{3}$ como nos casos aqui avaliados. Na situação particular do IMIP, esta oportunidade se torna um tanto singular, pela existência de uma enfermaria especial de tratamento hospitalar da desnutrição grave, segundo as normas do protocolo da Organização Mundial da Saúde (OMS). ${ }^{20}$

Assim contextualizada, a ocorrência de CIC anormal em $46,3 \%$ das crianças representa um componente importante na compreensão e, evidentemente, nos cuidados que devem ser atribuídos à carência concomitante da vitamina A no tratamento dos casos graves de DEP. É pertinente considerar que a DVA poderia ser ainda mais frequente, dado que $35 \%$ das crianças haviam recebido megadoses (100.000 a 200.000 UI de vitamina A) antes da admissão hospitalar. No entanto, ao mesmo tempo, cabe assinalar e lamentar a baixa cobertura do programa de suplementação de vitamina A, desde que se espera que, como ação básica, viesse a alcançar níveis de proteção semelhante à prática de vacinação, protegendo de $90 \%$ a $100 \%$ da população exposta.

Desafortunadamente, não se dispõe de estudos semelhantes e atuais sobre o problema da DVA em crianças hospitalizadas com DEP, usando a CIC como indicador do processo carencial específico em nível subclínico. Ademais, como a CIC representa uma técnica diagnóstica recente, a bibliografia a este respeito é ainda escassa. No caso do Brasil, ressaltam-se dois estudos de validação dessa técnica11,21 comprovando a utilidade da CIC como indicador da DVA, tendo os níveis de retinol sérico como padrão-ouro. No próprio IMIP, como resultado da experiência aqui relatada, detectou-se que $41,2 \%$ das crianças com desnutrição grave tinham níveis de retinol sérico abaixo de $0,70 \mu \mathrm{mol} / \mathrm{L}^{22}$ o que praticamente reflete a própria ocorrência de CIC anormal. Em nível de avaliações populacionais, a maior parte dos raros estudos existentes ainda são focalizados na questão da validação da técnica citológica como indicador presuntivo da DVA. Assim, na Venezuela, Castejón et al. 23 encontraram $35,4 \%$ de crianças de dois a seis anos com resultados anormais da CIC, sendo que $11,3 \%$ dessas crianças eram portadoras de formas leves de desnutrição. Um outro estudo na Venezuela chegou a um resultado conflitivo, desde que a maior prevalência $(25,6 \%)$ de CIC, envolvendo crianças de uma faixa etária mais avançada (49 a 72 meses) foi registrada em crianças com uma relação altura/idade normal. ${ }^{24}$ Em Teerã, no Irã, uma avaliação bem mais extensiva, aplicada em 1257 crianças de dois e cinco anos de idade, detectou uma prevalência de $23,5 \%$ de CIC anormal. ${ }^{1}$ Sem considerar o estado nutricional das crianças, Ajaiveoba et $a l ., 25$ na Nigéria, observaram que crianças portadores de CIC anormal apresentaram um risco de 2,6 vezes maior de níveis baixos de retinol sérico, quando comparadas com casos de CIC normal. Na realidade, a experiência acumulada ainda não é conclusiva para recomendar a prova da CIC como um recurso diagnóstico seguro para a detecção da DVA infraclínica, daí a recomendação da OMS de que, em estudos extensivos, devam ser aplicados pelo menos dois indicadores biológicos. 4

Duas outras observações devem ser discutidas. Uma, refere-se às doenças associadas às formas graves de DEP e, portanto, suas inter-relações com o 
próprio estado nutricional da vitamina A. Já é bem conhecida a relação etiopatogênica da DEP com a DVA: restrições alimentares comuns, principalmente por conta da situação de pobreza, bem ressaltada neste estudo de casos, e processos patogênicos agregados, comprometendo a ingestão, digestão, metabolismo, formação e utilização de reservas orgânicas, tornam-se praticamente autoexplicativos sobre da lógica da associação, como ressaltam Al-Kubaisy et al.26 Especificamente, cabe assinalar que quase metade das crianças com CIC anormal tinham edema, sendo presumível, pelo próprio quadro de desnutrição grave da casuística que, em grande parte, este sinal clínico, simetricamente localizado nos membros inferiores, seja manifestação de casos de desnutrição edematosa. Tratar-se-ia, portanto, de uma condição que afeta significativamente a utilização da vitamina $\mathrm{A}$, pela grande redução de seu "carrier",27 uma pré-albumina grandemente afetada na hipoalbuminemia, característica da desnutrição com edema.

Deve-se também considerar que um número considerável de casos (respectivamente 46,3\% e $31,7 \%$ ) das crianças internadas tinham diarréia ou pneumonia. São fatos importantes desde que, como processos infecciosos, são favorecidos pela DVA e, ao mesmo tempo, afetam rapidamente os níveis

\section{Referências}

1. Rostami N, Farsar AR, Shiva N. Prevalence of sub-clinical vitamin A deficiency in 2-5-year-old children in Tehran. East Mediterr Health J. 2007;13: 273-9.

2. Sommer A. Xerophtalmia, keratomalacia and nutritional blindness. Int Ophthamol. 1990; 14: 195-9.

3. West KP Jr. Extent of vitamin A deficiency among preschool children and women of reproductive age. J Nutr. 2002; 132 (suppl 9): 2857S-66S.

4. WHO (World Health Organization). Indicators for assessing vitamin A deficiency and their application in monitoring and evaluating intervention programmes. Geneva; 1996. (Micronutrient serie) (Doc WHO/NUT/96.10).

5. Ramalho RA, Flores H, Saunders C. Hipovitaminose A no Brasil: um problema de saúde pública. Rev Panam Salud Pública. 2002; 12: 117-22.

6. Batista Filho M, Miglioli TC. Alimentação e nutrição no Nordeste do Brasil. Recife: Liceu; 2006.

7. Martins MC, Santos LMP, Assis AMO. Prevalência da hipovitaminose A em pré-escolares no Estado de Sergipe, 1998. Rev Saúde Pública. 2004; 38: 537-42.

8. MacLaren DS, Frigg M. Sight and life manual on vitamin A deficiency disorders (VADD). 2 ed. Switzerland: Sight and Life; 2001.

9. Sommer A. Xerophtalmia and vitamin A status. Prog Retinol Eye Res. 1998; 17: 9-31. séricos de retinol. 28 Suas consequências em termos da CIC seriam de instalação mais tardia. Isto não descarta, no entanto, sua possível relação clínica e, sobretudo epidemiológica, de tal modo que a mortalidade por doenças infecciosas, especialmente diarréias e infecção respiratória aguda (IRA), é considerada como um dos indicadores indiretos da própria DVA. ${ }^{29,30}$ Finalmente, a constatação de que 43,9\% das crianças tinham uma doença de base, ou seja, uma doença de média ou severa gravidade, com uma importância clínica e duração prolongada, representa um importante fator de risco para a instalação da DEP grave e da DVA.

Conclusivamente, pode-se estabelecer que, ao lado dos resultados da CIC, outras evidências associadas justificam plenamente o cuidado de se administrar a vitamina A como um recurso importante no manejo hospitalar de crianças acometidas por formas graves de desnutrição. É possível que, ao lado de outros cuidados especiais propostos pela OMS20 para o tratamento hospitalar da desnutrição grave, a administração de vitamina A tenha contribuído para o marcante e até surpreendente declínio da mortalidade, baixando de valores basais de $36 \% 31$ para $4,9 \%$, conforme resultado da série de casos aqui estudada.

10. Calonge M, Diebold Y, Sáez V, Salamanca AE, GarcíaVázquez C, Corrales RM, Herreras JM. Impression cytology of the ocular surface: a review. Exp Eye Res. 2004; 78: 457-72.

11. Lóla MMF. Citologia de impressão conjuntival: uma contribuição ao diagnóstico precoce da xeroftalmia [dissertação]. Recife: Centro de Ciências da Saúde da Universidade Federal de Pernambuco; 1993.

12. Congdon NG, West KP Jr. Physiologic indicators of vitamin A status. J Nutr. 2002;132 (suppl 9): 2889S-94S.

13. McKelvie P. Ocular surface impression cytology. Adv Anat Pathol. 2003;10: 328-37.

14. NCHS (National Center for Health Statistics). Growth curves for children birth - 18 years. Vital Health Stat. 1977; 165: i-iv.

15. Oliveira MAA, Osório MM, Falcão MC. Concentração de hemoglobina e anemia em crianças no Estado de Pernambuco, Brasil: fatores socioeconômicos e de consumo alimentar associados. Cad Saúde Pública. 2006; 22: 2169 78.

16. Brasil. Ministério da Saúde. Pesquisa Nacional de Demografia e Saúde da Criança e da Mulher (PNDS), 2006. Capítulo 9. Amamentação e Alimentação. Brasília, DF; 2008. [26 nov 2008]. Disponível em: http://bvsms.saude. gov.br/bvs/pnds/img/relatorio final pnds2006.pdf 
17. Brasil. Ministério da Saúde. Secretaria de Vigilância em Saúde. Departamento de Análise de Situação em Saúde. Uma Análise da desigualdade em Saúde. Saúde Brasil 2006. Brasília, DF; 2006. [8 mai 2009]. Disponível em http://portal.saude.gov.br/portal/arquivos/pdf/saude_brasil 2006.pdf

18. UNICEF (Fundo das Nações Unidas para a Infância). Situação Mundial da Infância, 2008. Sobrevivência infantil. Brasília, DF; 2008. [8 mai 2009]. Disponível em: http://www.unicef.org/brazil/pt/sowc2008_br.pdf

19. Barros DC, Saunders C, Leal MC. Avaliação nutricional antropométrica de gestantes brasileiras: uma revisão sistemática. Rev Bras Saúde Matern Infant. 2008; 8: 363 76

20. OMS (Organização Mundial da Saúde). Manejo da desnutrição grave: um manual para profissionais de saúde de nível superior e suas equipes auxiliares. Genebra; 2000.

21. Araújo R, Diniz AS, Santos MLP. Diagnóstico e evolução de casos de ceratomalacia e xeroftalmia. J Ped. 1984; 57 419-23.

22. Caminha MFC, Diniz AS, Falbo AR, Arruda IK, Serva VB, Albuquerque LL, Freitas Lola MM, Ebrahim GJ. Serum retinol concentrations in hospitalized severe protein-energy malnourished children. J Trop Pediatr. 2008; 54: 248-52.

23. Castejón HV, Ortega P, Díaz ME, Amaya D, Gómez G Ramos M, Alvarado MV, Urrieta JR. Prevalência de deficiência subclínica de vitamina A desnutrición em niños marginales de Maracaíbo - Venzuela. Arch Latinoam Nutricion. 2001; 51: 25-32

24. Amaya-Castellanos D, Viloria-Castejón H, Ortega P, Gómez G, Urrieta JR, Lobo P, Estevez J. Deficiência de vitamina A y estado nutricional antropométrico em niños marginales urbanos y rurales em El Estado Zulia, Venezuela. Invest Clin. 2002; 43 89-105.
25. Ajaiveoba AI, Samaila E, Adeyefa AI. Conjunctival impression cytology and biochemical assessment of vitamin A status in Nigerian children. Niger J Med. 2002; 11: 63-6.

26. Al-Kubaisy W, Al-Rubaiy MG, Nassief HÁ. Xerophthalmia among hospitalized Iraqi children. East Mediterr Health J. 2002; 8: 496-502

27. Reid M, Badaloo A, Forrester T, Morlese JF, Heird WC, Jahoor F. The acute-phase protein response to infection in edematous and nonedematous protein-energy malnutrition. Am J Clin Nutr. 2002; 76: 1409-15.

28. Valbuena AA, Pereira N, Castillo J, Garcia D, Nuñez J, Cayama N, Morán A, Parra M, Troconiz C. Mediadores de inflamación (proteína c reativa) em el nino com desnutrición proteico-energética y em el niño eutrófico. Invest Clin. 2004; 45: 53-62.

29. Barreto ML, Santos LM. Effect of vitamin A supplementation on diarrhoea and acute lower-respiratory-tract infections in young children in Brazil. Lancet. 1994; 344: 22831 .

30. Silva R, Lopes EJr., Sarni ROS, Taddei JAAC. Níveis plasmáticos de vitamina A em crianças carentes com pneumonia na fase aguda e após recuperação. J Pediatr (Rio J). 2005; 81: 162-8.

31. Falbo AR, Alves JG, Batista Filho M, Caminha MFC, Cabral-Filho JE. Decline in hospital mortality rate after the use of the World Health Organization protocol for management of severe malnutrition. Trop Doct. 2009; 39: 71-2.

Recebido em 14 de abril de 2009

Versão final apresentada em 13 de maio de 2010

Aprovado em 6 de julho de 2010 